Denise Sese, MD

Education Institute, Cleveland Clinic
Mahwish U. Ahmad MD, MPH

Center for Bioethics, Community Care Institute, Cleveland Clinic
Prabalini Rajendram, MD

Critical Care Medicine, Emergency Services Instititute,

Cleveland Clinic

\title{
Ethical considerations during the COVID-19 pandemic
}

\section{Posted May 26, 2020}

\section{ABSTRACT}

The care of patients during the COVID-19 pandemic has added many layers of complexity to ethical issues. Our response emphasizes the importance of having an ethically sound framework to inform our decisions, requiring caregivers to consider what is ethically optimal and feasible for the patient. It is increasingly important to understand the ethical principles and to appropriately apply them to both patient management decisions and guide scarce resource allocation. If we are to be prepared to face the many challenges of this pandemic, we must prioritize the ethical demands to our treatment and management concerns.

\section{CLINICAL ETHICS DURING A PANDEMIC}

Challenging ethical issues in healthcare are common because central to our role as caregivers is the relief of human suffering. Reviewed on a global scale, ethical issues surrounding pandemics are not unique to our healthcare systems, neither are the ethical issues surrounding scarce resource allocation. The concept of scarce resource allocation has value-incorporation, as shown during World War II when the US production of penicillin was not enough to meet all the need, with $90 \%$ being used for soldiers. This demonstrates the promotion of instrumental value (saves the most lives because soldiers were most valuable at that time) in allocation. ${ }^{1}$

As part of an anticipated response to the effects of the COVID-19 pandemic, the importance of having an ethically sound framework to inform our clinical decisions cannot be emphasized enough. During this time, healthcare leaders are asked to engage in proac-

The statements and opinions expressed in COVID-19 Curbside Consults are based on experience and the available literature as of the date posted. While we try to regularly update this content, any offered recommendations cannot be substituted for the clinical judgment of clinicians caring for individual patients.

doi:10.3949/ccjm.87a.ccc038 tive planning where addressing worst-case scenarios is the first step to reducing morbidity, mortality, and other undesirable effects of an emerging public health emergency. ${ }^{2}$

\section{POPULATION HEALTH VS INDIVIDUAL RIGHTS}

A public health emergency, such as a surplus of people seeking healthcare as well as critically ill patients with COVID-19 or another severe respiratory illness requiring admission to the intensive care unit (ICU), disrupts normal processes for supporting ethically sound patient care due to the steeply rising supply demand gap for treatment or supportive measures. ${ }^{3}$ The ethical framework in a public health crisis shifts to promoting the health of the population by using resources responsibly to maximize the total number of lives saved. Understanding the guiding principles surrounding public health ethics may help promote trust and alleviate moral distress and burn-out in bedside providers under austere circumstances. ${ }^{4}$ The focus of public health ethics, can require limitations on individual rights and preferences due to need for prudent use of resources and strategies. ${ }^{3}$ These limitations must be consistently and equitably applied, be proportional, necessary, and relevant. ${ }^{5}$

\section{PRIORITIES OF HEALTHCARE PROVIDERS}

During pandemics, the priorities of healthcare providers change. Shifts in these priorities create competing obligations for providers who are naturally geared towards focusing on their individual patients. Policy planners are asked to consider the two competing ethical obligations that must be held in balance (for the sake of brevity we only consider the two primary obligations listed here but concede that other ethical obligations exist):

- Duty to care-relief of suffering and respect for the rights and preferences of patients, which is a focus of ethics consultation services. 
- Duty to promote equity and moral equalityfairness relative to need in the distribution of risks and benefits of care provision in society, which is the focus of public health ethics. ${ }^{3}$

Ethical reasoning thus requires caregivers to consider what should be ethically optimal and feasible for the patient. This is known as the crisis standard of care-a recognition of limitations during times of scarcity. ${ }^{6}$ In addition to duty to care and fairness, this ethical guidance is also based on duty to steward resources, transparency, consistency, proportionality, and accountability. ${ }^{2}$ As an ethical concept, it offers concrete guidance for a system-wide response to a disaster, addressing allocation.

\section{- ETHICAL PRINCIPLES GUIDING PATIENT MANAGEMENT IN A PANDEMIC}

The severe acute respiratory syndrome (SARS) outbreak in 2003 exposed the healthcare systems' vulnerabilities, revealing the need for coordinated and cooperative responses across national borders. As such, the Pandemic Influenza Working Group at the University of Toronto Joint Centre for Bioethics was formed. They created a document that provides a framework for values at risk during a pandemic. ${ }^{5}$ This is being used as a framework for ethical decisionmaking during the COVID-19 pandemic (Table 1).

\section{ETHICAL PRINCIPLES REGARDING SCARCE RESOURCE ALLOCATION}

A majorly anticipated ethical dilemma is the allocation of finite resources, defined as measures, rationale, or means by which resources or access to care is obtained by individuals to exclude others in a time of crisis. ${ }^{6}$ Estimates indicate that a moderate pandemic would infect 64 million Americans and necessitate hospitalization of 800,000 (1.25\%) with $160,000(0.25 \%)$ needing space in the intensive care unit (ICU). ${ }^{7}$ With dwindling resources as hospitals approach surge capacity, it is likely that an increased need will cause competition for resources such as testing, personal protective equipment (PPE), ventilators, vaccines, and ICU beds. Ethical principles that guide resource allocation are well-described in the literature (Table 2) ${ }^{8-11}$ Ultimately, we stress that no single value stands alone in determining which patients should receive scarce resources.

\section{APPLYING ETHICAL PRINCIPLES TO RESOURCE ALLOCATION}

It is important to remember that context will determine the crisis standard of care in order to apply ethi- cal frameworks to our decisions. Thus, it is important to stress how pandemic-associated priority shifts will lead to the selection of ethical principles guiding institutional- and clinician-driven patient-level decisions. The current overarching goal is to "privilege the greater chance to successfully overcome critical illness with a greater probability of maintaining a good quality of life." ${ }^{13}$

Redefining our approach to individual patient care while adhering to the principles of clinical appropriateness and proportionality of care happens as we move between the three operational stages in a pandemic: Conventional, contingency, and crisis. ${ }^{14}$ Like Italy, we must contextualize and account for the current disease severity, comorbidity, and the presence and reversibility of organ failures when allocating crucial resources.

\section{Allocation of ICU resources (beds and ventilator)}

The potential for recovery should be part of a patient's criteria for ICU admission. This approach will be a conscious shift, taken deliberately so as to not pursue our usual framework of ICU admission and care on a "first-come, first-served" basis. This shift in the care model is indicative of the health emergency nature of the care provision, as illustrated by Italy, which, in March 2020, struggled with being the second most-affected country globally. ${ }^{13}$ Clinical decision support systems in triage decision-making with validated criteria for limits (eg, Sequential Organ Failure Assessment (SOFA) scores, Multi-Organ Dysfunction Prediction Score (MODS), age) are helpful..11,15 As such, ventilator allocation, should follow the same principle as allocation of ICU beds to patients with higher chance of survival. Consideration of time-limited trials ${ }^{13}$ with clear communication of this ahead of time will address proportionality of care and enhance transparency to families. It is also important to state that all patients, regardless of COVID-19 status, should be treated similarly during the pandemic (ie, viewed with the same lens of chances of survivability) when it comes to consideration for ventilator and ICU bed allocation.

\section{Withdrawal of life-sustaining treatment}

Early consideration of a patient's history, current clinical course, expressed wishes, and expected goals are important when the patient is not responding to prolonged life-sustaining treatments. A consistent mechanism of streamlined de-escalation of care is important to have to guide clinician decisions. When a decision to withhold or withdraw life-sustaining 
TABLE 1

Anticipated ethical questions and responses to the COVID- 19 pandemic

\begin{tabular}{lll} 
Question & Value & Response \\
\hline $\begin{array}{l}\text { Are the restrictions on normal } \\
\text { activities ethically justified? }\end{array}$ & $\begin{array}{ll}\text { At risk: } \\
\text { Individual liberty } \\
\text { (integrity/empathy) }\end{array}$ & $\begin{array}{l}\text { Yes. Restrictions that impinge on individual liberty } \\
\text { should be applied equitably when relevant and neces- } \\
\text { sary to protect the public from serious harm. Personal } \\
\text { and professional practices must be regularly } \\
\text { reviewed and amended for the duration of the } \\
\text { pandemic to assure fairness of application. }\end{array}$ \\
& Overriding value: & Public health responsibilities
\end{tabular}

How much more restrictive can the measures ethically be for individuals and communities?

I don't want anyone to know I have COVID-19. Is it a HIPPA violation to report my diagnosis to public health officials?

Who has the greatest right to personal protective equipment?

How will public health officials and healthcare leaders decide how to distribute the resources if supplies become scarce?

What can the public expect regarding updates and communication about how healthcare institutions will make decisions?
At risk:

Justice and autonomy

(caregiver/empathy)

Overriding value:

Protection of the public from harm (safety/community)

At risk:

Privacy/integrity

Overriding value:

Obligations to our patients'

health

At risk:

Protection of all employees and community

Overriding value:

Duty to provide care

At risk:

Providing each patient what they need.

Overriding values:

Stewardship/utility/transparency

At risk:

Expending time and resources

Overriding value:

Open and transparent
In a public health crisis, healthcare organizations and public health authorities may be required to implement restrictions. Reasoning for the restrictions should be based on those minimally necessary to protect the public/individuals from the harm of infectiontransmission.

Not necessarily. In a public health crisis, the right to privacy typically afforded individuals may be overridden to protect the public from serious harm. Restrictions are the minimum necessary to accomplish public health goal with full transparency to patients.

Healthcare workers have a duty to care for the sick even when this places them at greater risk of harm. To mitigate these elevated risks, healthcare workers should be prioritized when distributing personal protective equipment.

The distribution of testing and treatment will be equitable and measured by the expectation of benefit. During a pandemic, the parameters for distribution of scarce goods may shift to a focus on rescue of the sick who are expected to recover.

Decisions should be made using an open and transparent process that is accessible to the public. The basis for procedural and allocation decisions will be based on evidence, principles, and shared values. treatments is made as a matter of good clinical practice, appropriate palliative care should be made available to hypoxemic patients.

\section{RESPONSIBILITY TO FAMILIES}

Communicating the definition of crisis standards of care to patients and families at admission is crucial to 
TABLE 2

Ethical principles used for resource allocation

\begin{tabular}{|c|c|c|c|}
\hline Allocation principle & Description example & Pros & Cons \\
\hline \multicolumn{4}{|l|}{ Treating people equally } \\
\hline Lottery & $\begin{array}{l}\text { Military draft, vaccinations, } \\
\text { employee drug screening }\end{array}$ & $\begin{array}{l}\text { Hard to corrupt; little } \\
\text { knowledge about recipients }\end{array}$ & $\begin{array}{l}\text { Blind to other factors and ignores } \\
\text { relevant principles }\end{array}$ \\
\hline $\begin{array}{l}\text { Waiting list on a } \\
\text { first-come, first-served } \\
\text { principle }\end{array}$ & ICU beds, organ allocation & $\begin{array}{l}\text { Favors those with access: } \\
\text { wealthy, powerful, and } \\
\text { well-connected }\end{array}$ & $\begin{array}{l}\text { Protects existing doctor-patient } \\
\text { relationships; exposes inequities } \\
\text { (lack of insurance, undesirable } \\
\text { groups such as prisoners) }\end{array}$ \\
\hline \multicolumn{4}{|c|}{ Favoring the worse off: Prioritarianism } \\
\hline Sickest first & $\begin{array}{l}\text { Emergency room triage, } \\
\text { organ allocation }\end{array}$ & $\begin{array}{l}\text { Priority to those suffering } \\
\text { right now; "rule of rescue"; } \\
\text { makes sense in temporary } \\
\text { scarcity; proxy for being worst } \\
\text { off overall }\end{array}$ & $\begin{array}{l}\text { Ignores needs of those who will } \\
\text { become sick in future; might falsely } \\
\text { assume temporary scarcity; leads to } \\
\text { people receiving interventions only } \\
\text { after prognosis deteriorates }\end{array}$ \\
\hline Youngest first & $\begin{array}{l}\text { ACIP pandemic flu vaccine } \\
\text { proposal }^{12}\end{array}$ & $\begin{array}{l}\text { Benefits those who have had } \\
\text { least life; prudent planners } \\
\text { have an interest in living to } \\
\text { old age }\end{array}$ & $\begin{array}{l}\text { Undesirable priority of infants over } \\
\text { adolescents and young adults } \\
\text { (eg, 2-month-old has less life than } \\
\text { 20-year-old but is prioritized) }\end{array}$ \\
\hline \multicolumn{4}{|c|}{ Maximizing benefits to all: Utilitarianism } \\
\hline $\begin{array}{l}\text { Prognosis (highest survival } \\
\text { probability and duration) }\end{array}$ & $\begin{array}{l}\text { Disaster triage, penicillin } \\
\text { distribution }\end{array}$ & Maximizes life years produced & $\begin{array}{l}\text { Ignores distributive principles; } \\
\text { does not consider number } \\
\text { of lives saved }\end{array}$ \\
\hline Number of lives saved & Bioterrorism response & $\begin{array}{l}\text { Avoids need to compare quality } \\
\text { of life; less time spent } \\
\text { deliberating }\end{array}$ & Ignores other principles \\
\hline \multicolumn{4}{|c|}{ Promoting and rewarding social usefulness } \\
\hline Behavior & $\begin{array}{l}\text { Gives priority to those who } \\
\text { did not engage in risky } \\
\text { behaviors that caused their } \\
\text { condition or affected it } \\
\text { negatively }\end{array}$ & $\begin{array}{l}\text { Promotes healthy lifestyle } \\
\text { and individual responsibility }\end{array}$ & $\begin{array}{l}\text { Ignores the reason for the } \\
\text { individual behavior }\end{array}$ \\
\hline Instrumental value & $\begin{array}{l}\text { PPEs to essential healthcare } \\
\text { workers during pandemics }\end{array}$ & $\begin{array}{l}\text { Serves saving most lives } \\
\text { because protects those } \\
\text { who can help save others }\end{array}$ & Prone to abuse \\
\hline Reciprocity & $\begin{array}{l}\text { Rewards irreplaceable people } \\
\text { who have served public }\end{array}$ & $\begin{array}{l}\text { Justice to people who have } \\
\text { contributed in the past }\end{array}$ & $\begin{array}{l}\text { Rewards only those who have } \\
\text { voluntarily provided societal } \\
\text { services in the past; requires time } \\
\text { to inquire }\end{array}$ \\
\hline
\end{tabular}

ICU = intensive care unit; PPE = personal protective equipment

fulfil our commitment to transparency. Complimentary services (eg, ethics service, palliative care teams) should be involved early to potentially decrease distress for the patient and family. This applies to all patients being cared for during the COVID-19 pandemic, regardless of COVID-19 status.

\section{Use of extra corporeal membrane oxygenation}

Extreme measures with little evidence and greater resource utilization (blood products, personnel, exposure) that portend poorer prognosis challenge the principle of maximizing benefits, which aims at saving the most individual lives or number of life-years by giving priority to patients likely to survive longest after treatment. ${ }^{9}$

\section{Need for tracheostomy}

In the context of COVID-19, a tracheostomy 
increases the number of healthcare providers exposed and increases PPE use, which at various stages of the pandemic might itself be a scarce resource. So tracheostomy would be a case-by-case decision point.

\section{ACCESS TO DIAGNOSTICS TESTING}

COVID-19 testing is currently available in Ohio; however, nationally, testing may become scarce, requiring it to be allocated according to the same principles noted previously. We initially prioritize testing based on supply and demand and operating level of the institution (conventional, contingency, crisis). Therefore at the onset, we reserved testing for the patients with the greatest disease burden. As we enter a more conventional level in which normal operations in institutions resume, patients who are not suspected to be COVID-19 positive may require testing to be allocated in order to safely allocate healthcare resources and minimize exposure (eg, being tested for COVID-19 prior to accessing healthcare settings for services such as chemotherapy infusions, invasive procedures, or surgery).

\section{RESPONSIBILITIES TO HEALTHCARE WORKERS: PPE, EXPOSURE RISK, PSYCHOLOGICAL AND MENTAL BURDEN}

Pandemics challenge our duty to provide care to patients versus the moral obligation to ourselves and our families, among other tensions. The risk of occupation-related infectious exposures reveal vulnerabilities for both patient and caregiver populations during a public health emergency. Such populations include older individuals, those with underlying health conditions, and existence of pre-existing barriers to health care owing to insurance or immigration status. Thus, healthcare workers are prioritized when distributing PPE because their specialized training lends instrumental valve in pandemic response, which in turn increases their perceived duty to provide care. ${ }^{5,9}$ If providers are sick, their smaller numbers will impair the crisis response, further diminishing our ability to maximize benefits for patients. Furthermore, the risk of quarantine and loss of income, transmission of the disease, and, possibly, death prove that the risk to front-line medical providers is both physical and psychological — both aspects of which should be considered.

\section{SUMMARY}

The care of patients during the COVID-19 pandemic has multiple layers of complexity. A shift in the perspectives of both patients and caregivers is necessary.
TABLE 3

\section{COVID-19 ethical resource allocation approach} at Cleveland Clinic

\section{Resource allocation}

- Recognize that pandemic crisis standards of care can interrupt access to care that is suspended temporarily in outpatient settings.

- Use a clinical decision support system in triage decisionmaking with validated criteria for limits (eg, SOFA scores, Multi-Organ Dysfunction Prediction Score (MODS), age). ${ }^{11,15}$

- Account for prognosis, comorbidities, and functional status in admission criteria to the ICU.

- $\quad$ Form triage teams that are distinct from bedside care team and are specific to allocation decision-making, to reduce moral distress during pandemic settings for the treating team.

Ethical responsibility to families

- $\quad$ Palliative care for discussions on advanced care planning or decision to withhold or withdraw life-sustaining treatments are done on an individual basis.

- Patients appropriately triaged to palliative care are notified of their right to discuss concerns or appeal decisions. In these situations, palliative care and ethics consultation services are readily accessible.

\section{Ethical responsibility to healthcare workers}

- Conservation and reallocation of resources make utilization more efficient and allow appropriate PPE to be made available to healthcare workers across settings such as the hospital, outpatient, long-term acute care facilities, and hospice.

If we are to be prepared to face the many challenges this pandemic will bring, we must prioritize the ethical demands of this disease as much as we do treatment and management concerns. Our Cleveland Clinic approach to resource allocation is summarized in Table 3. It aligns with guidelines from the Ohio Hospital association. ${ }^{16}$

\section{REFERENCES}

1. Persad G, Wertheimer A, Emanuel EJ. Principles for allocation of scarce medical interventions. Lancet 2009; 373(9661):423-431. doi:10.1016/S0140-6736(09)60137-9

2. Hick JL, Hanfling D, Wynia MK, Pavia AT; National Academy of Medicine. Duty to plan: health care, crisis standards of care, and novel coronavirus SARS-CoV-2. NAM Perspectives 2020. https://doi. org/10.31478/202003b

3. Berlinger N, Wynia M, Powell T, et al. Ethical framework for health care institutions responding to novel coronavirus SARS-CoV-2 (COVID-19). Guidelines for institutional ethics services responding to COVID-19. The Hastings Center. March 16, 2020. https://www. 
thehastingscenter.org/wp-content/uploads/HastingsCenterCovidFramework2020.pdf. Accessed May 13, 2020.

4. Daugherty Biddison L, Berkowitz KA, Courtney B, et al. Ethical considerations: care of the critically ill and injured during pandemics and disasters: CHEST consensus statement. Chest 2014; 146:e145Se155S. doi:10.1378/chest.14-0742

5. Upshur RE, Faith K, Gibson J, et al. Stand on guard for thee: ethical considerations in preparedness planning for pandemic influenza. A report of the University of Toronto Joint Centre for Bioethics Pandemic Influenza Working Group. http://jcb.utoronto.ca/publications/documents/stand_on_guard.pdf. Accessed May 14, 2020.

6. Leider JP, Debruin D, Reynolds N, Koch A, Seaberg J. Ethical guidance for disaster response, specifically around crisis standards of care: a systematic review. Am J Public Health 2017; 107(9):e1-e9. doi:10.2105/AJPH.2017.303882

7. Truog RD, Mitchell C, Daley GQ. The toughest triage-allocating ventilators in a pandemic. N Engl J Med 2020. doi:10.1056/ NEJMp2005689

8. Krütli P, Rosemann T, Törnblom KY, Smieszek T. How to fairly allocate scarce medical resources: ethical argumentation under scrutiny by health professionals and lay people. PLoS One 2016; 11(7):e0159086. doi:10.1371/journal.pone.0159086

9. Emanuel EJ, Persad G, Upshur R, et al. Fair allocation of scarce medical resources in the time of Covid-19. N Engl J Med 2020. doi:10.1056/nejmsb2005114

10. Biddison ELD, Gwon HS, Schoch-Spana M, et al. Scarce resource allocation during disasters: a mixed-method community engagement study. Chest 2018; 153(1):187-195. doi:10.1016/j.chest.2017.08.001

11. White DB, Katz MH, Luce JM, Lo B. Who should receive life support during a public health emergency? Ann Intern Med 2009; 150(2):132-138. doi: 10.7326/0003-4819-150-2-200901200-00011

12. US Department of Health and Human Services, Centers for Disease Control. Allocating and Targeting pandemic influenza vaccine during an influenza pandemic. https://www.cdc.gov/flu/pandemicresources/pdf/2018-Influenza-Guidance.pdf. Accessed May 14, 2020.

13. Vergano M, Bertolini G, Giannini A, et al. Clinical ethics recommendations for the allocation of intensive care treatments in exceptional, resource-limited circumstances: the Italian perspective during the COVID-19 epidemic. Crit Care 2020; 24(1):165. doi:10.1186/ s13054-020-02891-w

14. Maves RC, Downar J, Dichter JR, et al; ACCP Task Force for Mass Critical Care. Triage of scarce critical care resources in COVID-19 an implementation guide for regional allocation: an expert panel report of the Task Force for Mass Critical Care and the American College of Chest Physicians. Chest 2020. doi:10.1016/j.chest.2020.03.063

15. Hick JL, O'Laughlin DT. Concept of operations for triage of mechanical ventilation in an epidemic. Acad Emerg Med 2006; 13(2):223229. doi:10.1197/j.aem.2005.07.037

16. Ohio Hospital Association. Guidelines for allocation of scarce medical resources. Published 2020. https://www.ohiohospitals. org/OHA/media/OHA-Media/Documents/Patient Safety and Quality/COVID19/Ohio-Guidelines-for-Allocation-of-Scarce-MedicalResources-CLEAN-FINAL.pdf. Accessed May 14, 2020. 